\title{
Aplicação de boro e reposição de água no solo na cultura do milho forrageiro
}

Márcio José de Santana ${ }^{1}$

Amanda Letícia da Silveira ${ }^{2}$

Hérica Patrícia Oliveira dos Reis ${ }^{3}$

\section{Resumo}

Dentre os tratos culturais, a irrigação e a adubação tornam-se imprescindíveis durante a condução da cultura do milho. Dentre os nutrientes, o boro exerce um papel importante no crescimento das plantas. Objetivou-se avaliar o desempenho do milho forrageiro (até a fase de corte para volumoso), submetido a diferentes concentrações de boro e níveis de reposição de água. 0 delineamento experimental foi inteiramente casualizado com 16 tratamentos $(4 \times 4)$, sendo testadas quatro reposições de água no solo (70\%, 100\%, 130\% e 160\% da evapotranspiração diária) e quatro doses de boro (0 mg dm $\mathrm{m}^{-3} ; 0,5 \mathrm{mg} \mathrm{dm}^{-3} ; 1,0 \mathrm{mg} \mathrm{dm}^{-3}$ e 1,5 $\mathrm{mg} \mathrm{dm}^{-3}$ ) com quatro repetições. As variáveis avaliadas foram matéria verde e seca aos 35, 55 e 90 dias após semeadura (DAS) e a eficiência do uso da água (E.U.A.). A cultura do milho, cultivar 30F90, é sensível tanto ao déficit quando ao excesso de água de irrigação; quando se irrigou com 70\% de reposição, houve maior E.U.A.; aos 90 DAS a reposição estimada que proporcionou maior média de matéria seca foi de 113,6\% com dose de boro de 0,69 mg dm

Palavras-chave: Manejo irrigação. Zeamays. Boro.

\section{Introdução}

O milho (Zeamays) pertencente à família Poaceae é uma das mais importantes culturas utilizadas na alimentação animal, possuindo um ciclo curto, com alto potencial produtivo, sendo muito cultivada no Brasil. Uma das formas de sua utilização é como silagem (ou volumoso). 0 milho é cultivado em climas que variam desde a zona temperada até a tropical, durante o período em que as temperaturas médias diárias são superiores a $15^{\circ} \mathrm{C}$ e livres de geadas. No sudeste do Brasil, o cultivo do milho em sucessão a grandes culturas tem se mostrado uma alternativa para os agricultores, permitindo o aproveitamento de áreas irrigadas ou na entressafra (SILVA et al., 2000).

No seu cultivo deve-se atentar para o manejo de água no solo, bem como, o manejo nutricional. 0 bom manejo de irrigação aumenta a produtividade em aproximadamente $30 \%$. Atualmente as chuvas estão mal distribuídas ou insuficientes e isso intervém de forma direta na produção agrícola no Brasil. Nos últimos anos, tem aumentado significativamente o cultivo do milho sob irrigação, promovendo algumas alterações nas formas de manejo das lavouras, através do planejamento de uso mais intensivo das áreas para compensação do alto investimento, com maior número de cultivos e culturas envolvidas e possibilidade de uso de doses mais elevadas de fertilizantes (PAVINATO et al., 2007).

Quando o déficit hídrico ocorre durante o período crítico da cultura, a produtividade é afetada. Nessas condições o uso da irrigação torna-se fundamental, pois é no período crítico que ocorrem os maiores efeitos do déficit hídrico e também a maior eficiência do uso da irrigação, tanto na produção de matéria seca quanto na produtividade de grãos (BERGONCI; BERGAMASCHI, 2002).Há um período durante o ciclo da cultura em que mais água é consumida diariamente. No caso do milho, esse período coincide com o florescimento e o enchimento de grãos. A quantidade de água usada pela cultura, por unidade de tempo nesse período é chamada demanda de pico. 0 milho é considerado

${ }^{1}$ Prof. Dr. Irrigação e Drenagem, IFTM, Campus Uberaba, MG, marciosantana@iftm.edu.br, Unidade I Rua João Batista Ribeiro n. 4000 - Distrito Industrial II. - CEP: 38.064-790 Uberaba-MG.

²Engenheira Agrônoma, Mestranda em Produção Vegetal, UNESP Jaboticabal, SP, amandaagronomia@gmail.com, Faculdade de Ciências Agrárias e Veterinárias, Campus de Jaboticabal. Via de Acesso Prof. Paulo Donato Castellane, CEP 14884-900, Jaboticabal, SP. ${ }^{3}$ Estudante IFTM Campus Uberaba, MG. Unidade I - Rua João Batista Ribeiro n. 4000 - Distrito Industrial II. CEP: 38.064-790 Uberaba-MG. 
uma cultura que demanda muita água, mas também é uma das mais eficientes no seu uso, isto é produz uma grande quantidade de matéria seca por unidade de água absorvida. 0 milho de variedade de ciclo médio cultivado para a produção de grãos secos consome de $400 \mathrm{~mm}$ a $700 \mathrm{~mm}$ de água em seu ciclo completo, dependendo das condições climáticas(ALBUQUERQUE; ANDRADE, 2001).

Dentre os nutrientes, o boro é um dos que mais se encontram deficientes em solos brasileiros. Há uma relação direta entre este nutriente e a quantidade de água no solo. A deficiência desse micronutriente pode interferir no crescimento e desenvolvimento da planta.

Para Furtini Neto et al. (2001) na faixa de pH da maioria dos solos cultivados, o boro ocorre na solução do solo na forma de ácido bórico não dissociado. É, portanto, o único nutriente que ocorre na solução na forma neutra. Por esta razão, é um micronutriente muito susceptível a perdas por lixiviação. Ao que tudo indica, o boro é absorvido pelas plantas na forma $\mathrm{H}_{3} \mathrm{BO}_{3}$ e seu transporte na solução ocorre predominantemente por fluxo de massa. O limite entre a toxidez e a essencialidade do boro é muito estreito.

O objetivo desse trabalho é o de avaliar o desempenho do milho destinado ao uso na alimentação animal (volumoso/silagem) submetido a diferentes reposições de água no solo e doses de boro.

\section{Material e Métodos}

O experimento foi conduzido entre os meses de março e maio de 2011, em uma casa-devegetação localizada no Instituto Federal do Triângulo Mineiro, campus Uberaba, MG. O mesmo localiza-se a 800 metros de altitude, com latitude de 19 39' 19"S e longitude de 470 57' 27"W. O clima do local, segundo classificação de Köppen, é do tipo tropical quente e úmido, com inverno frio e seco (Aw), com precipitação e temperatura média anual de $1580 \mathrm{~mm}$ (aproximadamente) e $21^{\circ} \mathrm{C}$, respectivamente.

O solo utilizado foi caracterizado como um Latossolo Vermelho distroférrico, o qual foi peneirado e adicionado calcário para a correção da acidez de acordo com análise química realizada no Laboratório de Análise de Fertilidade de Solo da EPAMIG, em Uberaba, MG (Tabela 1). 0 solo foi coletado em uma área de barranco próxima ao IFTM - Campus Uberaba, evitando possíveis contaminações. 0 mesmo foi peneirado e colocado em vasos de polietileno.Antes da semeadura foi realizada uma calagem utilizando carbonato de cálcio, adicionando aproximadamente 9,0 gramas em cada vaso, com um tempo de reação de 20 dias.

Tabela 1 - Resultados da análise da fertilidade do solo. EPAMIG, Uberaba, MG. 2011.

\begin{tabular}{|c|c|}
\hline Características & Valores \\
\hline pH em água & 5,4 \\
\hline $\mathrm{Al}\left(\mathrm{cmolc} \mathrm{dm}^{-3}\right)$ & 0,1 \\
\hline $\mathrm{Ca}\left(\mathrm{cmolc} \mathrm{dm}^{-3}\right)$ & 0,4 \\
\hline $\mathrm{Mg}\left(\mathrm{cmolc} \mathrm{dm}^{-3}\right)$ & 0,2 \\
\hline $\mathrm{H}+\mathrm{Al}\left(\mathrm{cmolc} \mathrm{dm}^{-3}\right)$ & 1,7 \\
\hline $\mathrm{SB}\left(\mathrm{cmolc} \mathrm{dm}^{-3}\right)$ & 0,6 \\
\hline $\mathrm{t}\left(\mathrm{cmolc} \mathrm{dm}^{-3}\right)$ & 0,7 \\
\hline $\mathrm{T}\left(\mathrm{cmolc} \mathrm{dm}^{-3}\right)$ & 2,3 \\
\hline $\mathrm{K}\left(\mathrm{mg} \mathrm{dm}^{-3}\right)$ & 12,0 \\
\hline$P\left(\mathrm{mg} \mathrm{dm}^{-3}\right)$ & 0,4 \\
\hline P-rem $\left(\mathrm{mg} \mathrm{L}^{-1}\right)$ & 12,4 \\
\hline $\mathrm{V}(\%)$ & 27,1 \\
\hline m (\%) & 13,7 \\
\hline M.O. (dag kg $\left.{ }^{-1}\right)$ & 0,7 \\
\hline C.Org (dag kg $\left.{ }^{-1}\right)$ & 0,4 \\
\hline
\end{tabular}

*SB = soma de bases trocáveis; * $\mathrm{t}=$ capacidade de troca catiônica efetiva; * $\mathrm{T}=$ capacidade de troca catiônica a pH 7,0; * V = índice de saturação por bases.

Fonte: EPAMIG, Uberaba, MG. 
A adubação de plantio consistiu em adicionar toda dose de magnésio e de fósforo e mais $1 / 3$ da dose do potássio e do nitrogênio 10 dias antes da semeadura. Para a adubação de condução foi utilizada a recomendação de Malavolta (1980), fornecendo os nutrientes nas seguintes doses, em $\mathrm{mg} \mathrm{dm^{-3 }}: \mathrm{N}=300 ; \mathrm{P}=200 ; \mathrm{K}=150 ; \mathrm{Ca}=75 ; \mathrm{Mg}=15 ; \mathrm{S}=50 ; \mathrm{Cu}=1,5 ; \mathrm{Fe}=1,5 ; \mathrm{Mn}=$ 3,0; Mo $=0,1$ e $Z n=5,0$. O restante do nitrogênio e potássio foi aplicado em duas doses de cobertura. Os demais nutrientes foram adicionados três dias após a semeadura (DAS). As doses experimentais de boro foram divididas e aplicadas três dias após a semeadura e aos 15 dias após semeadura. As fontes utilizadas foram: ureia, superfosfato triplo, cloreto de potássio, sulfato de magnésio, sulfato de cobre, sulfato de manganês, molibdato de sódio, sulfato de zinco e ácido bórico.Para controle de pragas e doenças, foram utilizados os produtos Deltamethrin e Mancozeb, respectivamente.

A curva de retenção de água no solo foi determinada no Instituto Federal de Educação, Ciência e Tecnologia do Triângulo Mineiro, em Uberaba, MG (Laboratório de Solos). Para tensões de 2, 4, 6, 8 e $10 \mathrm{kPa}$ foi utilizado o método do funil de placa porosa (Funil de Haines) e, para as tensões de 33, 100, 500 e 1500 kPa, a câmara de pressão de Richards. Com o aplicativo Soil Water Retention Curve (SWRC), desenvolvido por Dourado Neto et al. (1995). Obteve-se a Equação 1, ajustada segundo o modelo de Genutchen (1980), que descreve a umidade do solo em função do potencial matricial. A curva de retenção da água no solo é mostrada na Figura 1.

$$
\theta(h)=0,220+\frac{0,37}{\left[1-(0,59 h)^{5,6}\right]^{0,21}}
$$

em que:

$\boldsymbol{\theta}(\mathrm{h})$ - umidade do solo $\left(\mathrm{kg} \mathrm{kg}^{-1}\right)$ para um dado valor de h e, $\mathrm{h}$ - módulo potencial mátrico $(\mathrm{kPa})$.

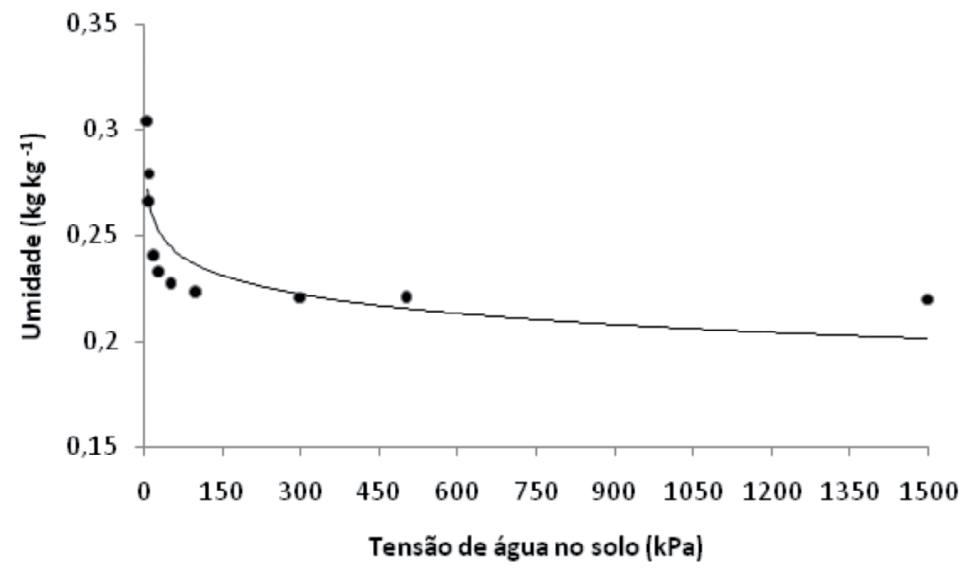

Figura 1 - Curva de retenção da água no solo utilizado no experimento. Uberaba, MG, 2011.

Fonte: Elaboração dos autores.

A densidade média do solo foi obtida após adicioná-lo ao recipiente (vaso de polietileno), obtendo-se um valor de 0,98 $\mathrm{Mg} \mathrm{m}^{-3}$. A cultivar empregada foi o híbrido 30F90, que é um híbrido simples, com precocidade na colheita e com potencial para produção de grãos e silagem.

O início do experimento foi caracterizado por elevar a umidade do solo dos vasos à capacidade de campo; para isso, eles foram saturados com água, envolvidos individualmente com plástico, de forma a forçar a perda de água apenas por drenagem. Finalizando a drenagem, após aproximadamente dois dias, os plásticos foram retirados e a semeadura foi realizada (GERVÁSIO et al., 2000).

Foram adicionadas cinco sementes ao solo e após o estabelecimento ("pegamento"), foram deixadas apenas três plântulas para condução experimental.

0 experimento foi conduzido em um delineamento inteiramente casualizado (DIC) com quatro repetições, sendo empregado um esquema fatorial de $4 \times 4$ (dois fatores), constituído por quatro reposições de água no solo (70\%, 100\%, 130\% e 160\% da evapotranspiração diária) e quatro doses de boro aplicadas ao solo ( $0 \mathrm{mg} \mathrm{dm}^{-3} ; 0,5 \mathrm{mg} \mathrm{dm}^{-3} ; 1,0 \mathrm{mg} \mathrm{dm}^{-3}$ e 1,5 $\mathrm{mg} \mathrm{dm}^{-3}$ ), totalizando 64 parcelas. 0 emprego das doses de boro foi baseado na recomendação de Malavolta (1980), que sugere adicionar 0,5 $\mathrm{mg} \mathrm{dm}^{-3}$. Cada parcela foi constituída de um vaso de polietileno com capacidade para $14 \mathrm{dm}^{3}$, com três plantas que foram cortadas para determinação das variáveis. Aos 35, 55 e 90 DAS 
uma planta de cada vaso foi arrancada e pesada, obtendo-se a matéria verde. Posteriormente, foram secas em estufa a $65^{\circ} \mathrm{C}$ e, após pesagem, obteve-sea matéria seca. Para encontrar a eficiência do uso da água foi obtida uma relação da produtividade média de matéria seca (massa) aos 90 DAS e 0 respectivo consumo de água durante o período estudado (diferentes reposições de água no solo).

Foi instalado um termohigrômetrona área experimental para coletas de umidade e temperatura do ar (máxima e mínima). As leituras foram realizadas diariamente pela manhã.

Os volumes de água de reposição para cada vaso foram obtidos a partir de um percentual (relativo a cada tratamento) da quantidade de água evapotranspirada diariamente; para isso instalaramse em três vasos dos tratamentos $100 \%$ e dose de boro de $0,5 \mathrm{mg} \mathrm{dm}^{-3}$, drenos de coleta da água de percolação, para a estimativa da evapotranspiração e do balanço de água no solo conforme Equação 2 (GERVÁSIO et al., 2000; SANTANA, 2004). A reposição de água foi realizada manualmente, todos os dias, com auxílio de uma proveta graduada.

$$
\mathrm{ET}=\mathrm{I}-\mathrm{D}
$$

em que,

ET é a água evapotranspirada diária $(\mathrm{mL}=>$; I é a quantidade de água aplicada $(\mathrm{mL})$ e $\mathrm{D}$ é a quantidade de água drenada $(\mathrm{mL})$.

Foram instaladas três hastes tensiométricas, sendo uma por vaso $=>$, a 0,2 $\mathrm{m}$ de profundidade, para medidas da tensão de água no solo em cada tratamento. As leituras foram realizadas por meio de um tensímetro de punção (digital).

Foram realizadas análises de variância para as médias dos parâmetros avaliados, matéria seca e verde das plantas, utilizando-se o teste de distribuição F a $5 \%$ de probabilidade. Para comparação das médias consideradas, usou-se teste de regressão.

\section{Resultados e Discussões}

A temperatura máxima média observada na área experimental, dentro da casa de vegetação, foi de $34,5^{\circ} \mathrm{C}$ e a mínima média de $11,2{ }^{\circ} \mathrm{C}$. Os valores estão na Figura 2, onde se pode notar que a temperatura média oscilou entre aproximadamente $17,0^{\circ} \mathrm{C}$ e $30,0{ }^{\circ} \mathrm{C}$. Segundo Sans e Santana (2007), temperaturas maiores que $35,0^{\circ} \mathrm{C}$ reduzem a atividade da redutase do nitrato, reduzindo o rendimento e a composição proteica da cultura do milho. Ainda segundo os mesmos autores, por ocasião da floração, temperaturas médias superiores a $26,0^{\circ} \mathrm{C}$ aceleram o desenvolvimento dessa fase e as inferiores a $15,5^{\circ} \mathrm{C}$ retardam-na. Até os 60 dias após semeadura, poucas vezes a temperatura média esteve superior a $22{ }^{\circ} \mathrm{C}$.

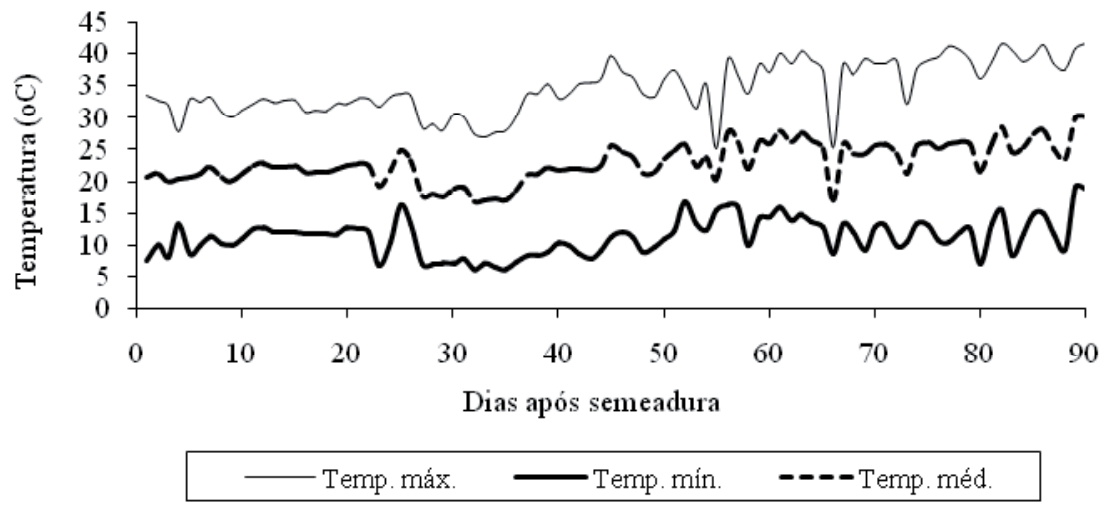

Figura 2 - Temperaturas média, máxima e mínima registradas durante a condução do experimento. Uberaba, MG, 2011.

Fonte: Elaboração dos autores.

Os valores de umidade relativa do ar estão na Figura 3. A umidade relativa média máxima foi de $83,4 \%$ e mínima de $12,4 \%$. 


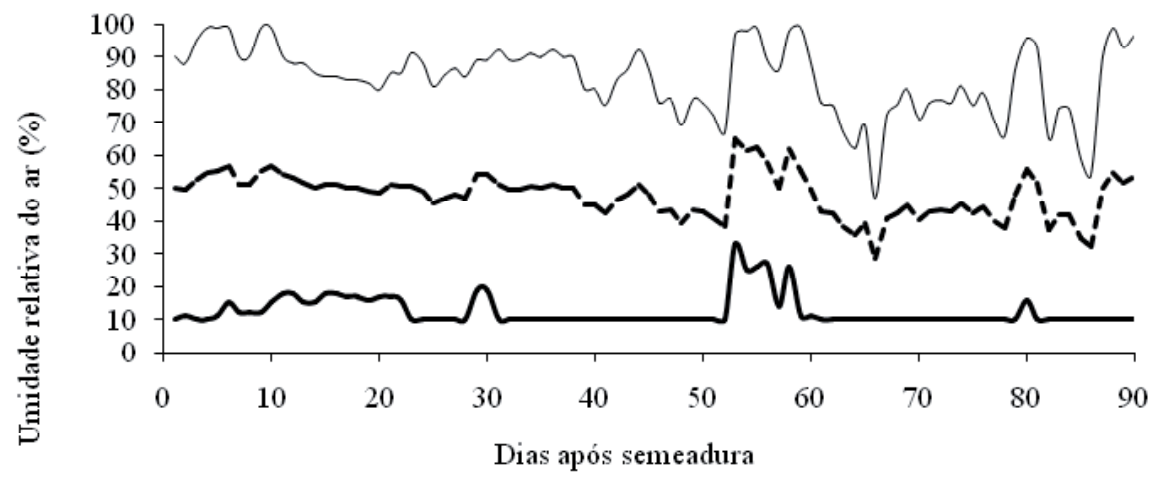

Umid. máx. —Umid. mín. - - ---Umid. méd.

Figura 3 - Umidades média, máxima e mínima registradas durante a condução do experimento. Uberaba, MG, 2011.

Fonte: Elaboração dos autores.

Os valores médios de tensão de água no solo para os tratamentos de reposição de $70 \%$, $100 \%, 130 \%$ e 160\% foram de 15,07 kPa; 9,48 kPa; 6,29 kPa e 4,57 kPa, respectivamente.

Sabe-se que a tensão de água ideal na cultura do milho varia de solo e local. Na literatura são encontrados valores de $33 \mathrm{kPa}$ (ANTONINI et al., 1997), $40 \mathrm{kPa}$ (GUERRA et al., 1997) e $70 \mathrm{kPa}$ (RESENDE et al., 1990). A umidade na capacidade de campo do solo do experimento foi de $0,25 \mathrm{~kg}$ $\mathrm{kg}^{-1} \mathrm{com}$ uma tensão média de 9,21 kPa. Dessa forma, a tensão média que aproximou da indicada a manter a capacidade de campo foi a do tratamento 100\%. Na Figura 4 estão as médias de tensão de água no solo, coletadas diariamente durante a condução do experimento.

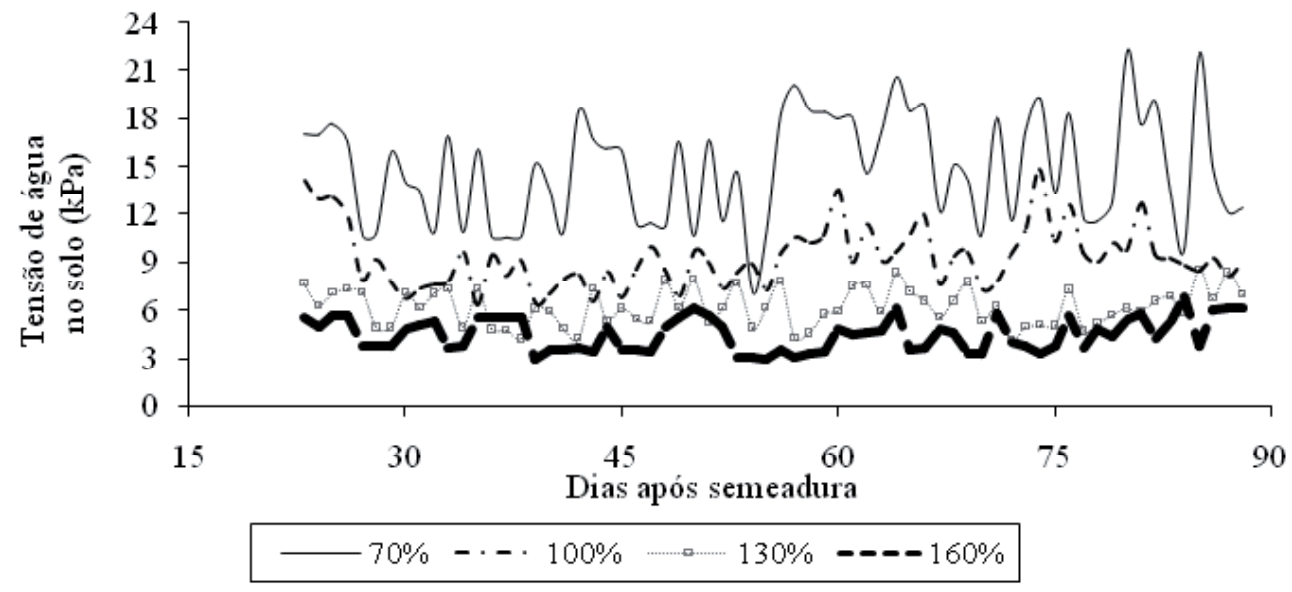

Figura 4 - Tensões de água no solo registradas durante a condução do experimento. Uberaba, MG, 2011. Fonte: Elaboração dos autores.

O consumo de água pelas plantas está representado na Figura 5. Houve uma tendência de aumento do consumo de água após os 60 dias de cultivo com posterior queda aos 86 DAS. Este período de maior consumo foi verificado no florescimento/início enchimento de grãos.

Conforme Bergamaschi et. al. (2004), o milho apresenta um período crítico no consumo de água, que vai da pré-floração ao enchimento de grãos. Ainda de acordo com os autores, irrigações realizadas durante o período de pendoamento até o período de enchimento de grãos permitem elevar a produtividade, mesmo que a umidade seja mantida abaixo da capacidade de campo. Assim, a cultura tem uma maior evapotranspiração e consequentemente um maior consumo de água nessa fase.

A lâmina total aplicada no tratamento de $100 \%$ foi de $897 \mathrm{~mm}$, acima do indicado por Sans e Santana (2007), que é de $500 \mathrm{~mm}$ a $800 \mathrm{~mm}$. Esse fato deve-se, provavelmente, ao volume de 
solo no recipiente utilizado, o que pode proporcionar aumento da evapotranspiração.

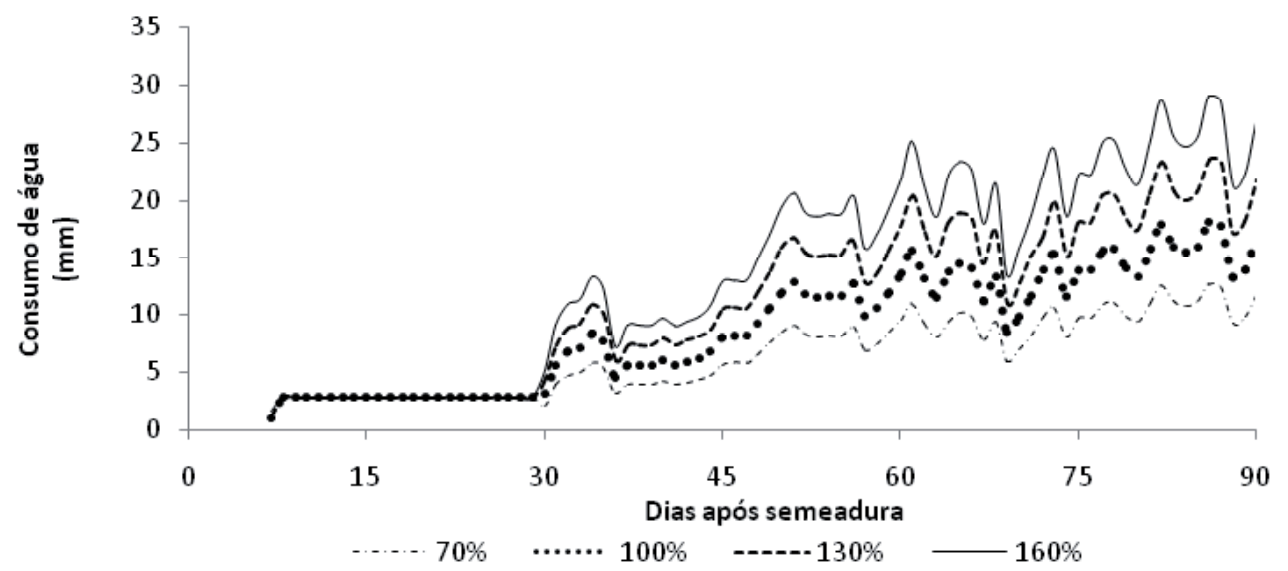

Figura 5 - Consumo de água nos diferentes tratamentos de reposição de água. Uberaba, MG, 2011. Fonte: Elaboração dos autores.

Na Tabela 2 está o resumo da análise de variância para matéria seca e verde das plantas coletadas aos 35, 55 e 90 DAS. Aos 35 DAS houve interação entre os fatores para matéria seca das plantas. Aos 55 e 90 DAS constatou-se diferença significativa entre as reposições e as doses de boro para matéria verde e seca.

Tabela 2 - Resumo da análise de variância dos dados relativos à matéria verde aos 35 DAS (MV35), matéria seca aos 35 DAS (MS35), matéria verde aos 55 DAS (MV55), matéria seca aos 55 DAS (MS55), matéria verde aos 90 DAS (MV90) e matéria seca aos 90 DAS (MS90).

\begin{tabular}{|c|c|c|c|c|c|c|}
\hline \multirow{2}{*}{$\begin{array}{l}\text { Fontes de } \\
\text { variação }\end{array}$} & \multicolumn{6}{|c|}{ Quadrado médio } \\
\hline & MV35 & MS35 & MV55 & MS55 & MV90 & MS90 \\
\hline Reposição (R) & $32,60^{\mathrm{NS}}$ & $2,41^{\mathrm{NS}}$ & $4381,44^{*}$ & $117,81^{*}$ & $30073,41^{*}$ & $27579,67^{*}$ \\
\hline $\begin{array}{l}\text { Doses de boro } \\
\text { (B) }\end{array}$ & $3,92^{\mathrm{NS}}$ & $\begin{array}{c}1583,8 \\
\text { NS }\end{array}$ & $1583,8^{*}$ & $98,7^{*}$ & $23651,8^{*}$ & $15303,8^{*}$ \\
\hline$R \times B$ & $64,46^{\mathrm{NS}}$ & $2,12^{*}$ & $398,7^{\mathrm{NS}}$ & $32,4^{\mathrm{NS}}$ & $15608,7^{\mathrm{NS}}$ & $3860,9^{N S}$ \\
\hline $\mathrm{CV}(\%)$ & 35,5 & 32,2 & 28,7 & 28,2 & 18,9 & 18,7 \\
\hline
\end{tabular}

$C V=$ coeficiente de variação; $N S=$ não significativo pelo teste $F ;{ }^{*}=$ significativo a $5 \%$ de probabilidade pelo teste F.

Fonte: Elaboração dos autores.

O maior ganho de matéria seca está relacionado com a reposição de 100\%. Nota-se (Figura 6) que tanto o déficit (70\% de reposição) quanto o excesso (lâminas maiores que 100\% de reposição) proporcionaram baixo rendimento para esta variável. Para Guimarães (1988), o déficit hídrico ocasiona murchamento das plantas, prejudicando sua fisiologia. Por outro lado, lâminas excessivas provocam um ambiente com falta de aeração para as plantas. 

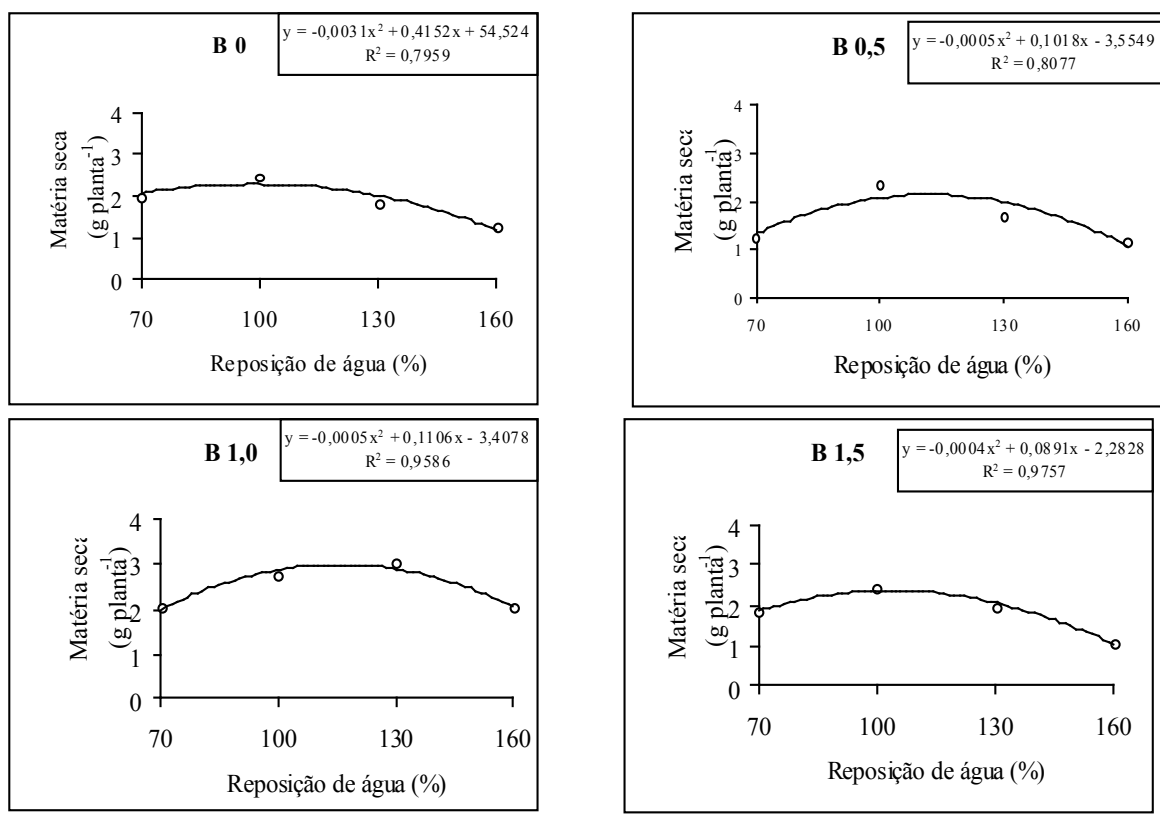

Figura 6 - Matéria seca das plantas aos 35 DAS em função da reposição de água para as diferentes doses de boro. Uberaba, MG, 2011.

Fonte: Elaboração dos autores.

Houve aumento da matéria seca das plantas aos 35 DAS com o aumento da aplicação de boro até valores próximos de 1,0 $\mathrm{mg} \mathrm{dm}^{-3}$ (Figura 7). Igualando-se a primeira derivada das equações das Figuras 6 e 7 a zero, pode-se obter os máximos rendimentos físicos.
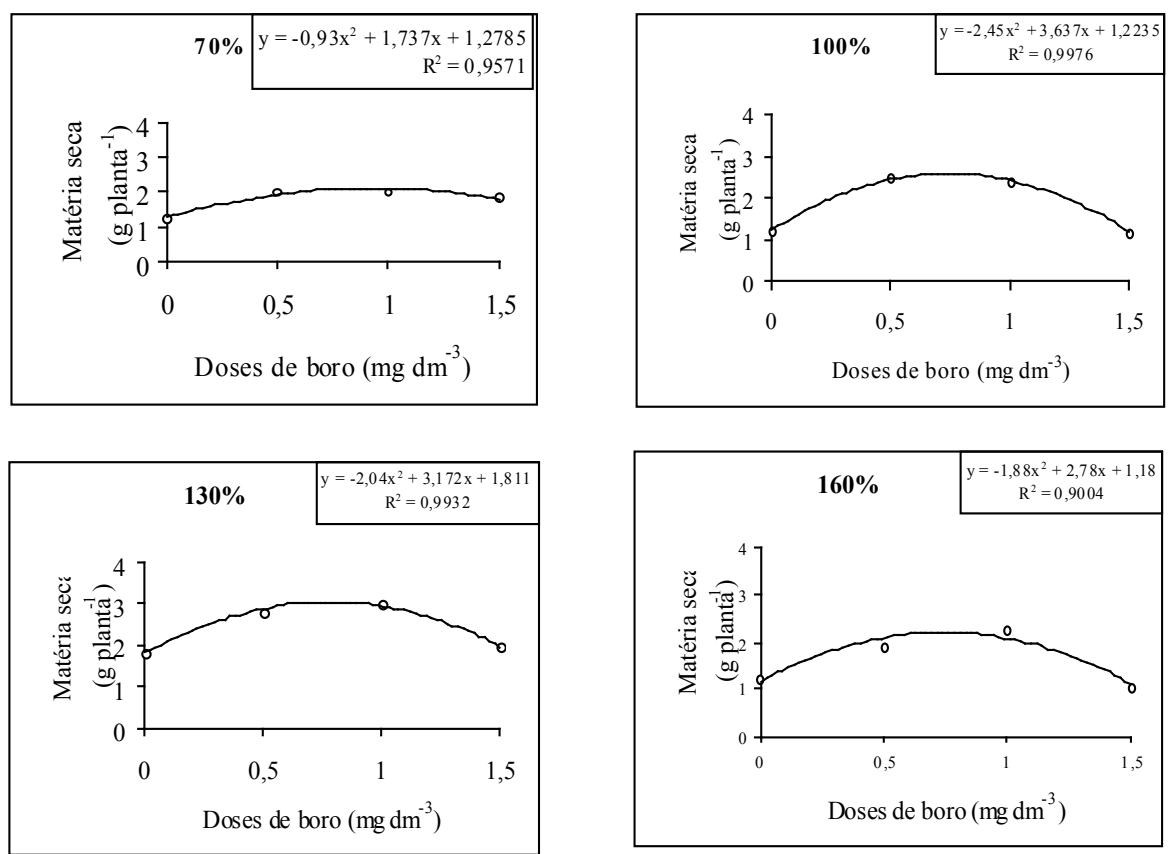

Figura 7 - Matéria seca das plantas aos 35 DAS em função das doses de boro para as reposições de água. Uberaba, MG, 2011.

Fonte: Elaboração dos autores.

Na Tabela 3 encontram-se as reposições de água no solo que proporcionaram a matéria seca ótima (máximo valor médio da matéria seca). Na mesma tabela encontram-se as doses de boro que 
proporcionaram as máximas matérias secas. Quando a reposição de água no solo foi de 100\%, constatou-se uma dose de boro de 0,74 $\mathrm{mg} \mathrm{dm}^{-3}$, diferindo da recomendada por Malavolta (1980).

Tabela 3 - Reposições de água e doses de boro estimadas. Uberaba, MG, 2011.

\begin{tabular}{cccccccc}
\hline \multicolumn{2}{c}{ MV55 $^{*}$} & \multicolumn{2}{c}{ MS55 } & \multicolumn{2}{c}{ MV90*** } & \multicolumn{2}{c}{ MS90 $^{* * * *}$} \\
\hline $\begin{array}{c}\text { Reposição } \\
\text { de água } \\
(\%)\end{array}$ & $\begin{array}{c}\text { Dose de } \\
\text { boro } \\
\left(\mathbf{m g ~ d m}^{-3}\right)\end{array}$ & $\begin{array}{c}\text { Reposição } \\
\text { de água } \\
(\%)\end{array}$ & $\begin{array}{c}\text { Dose de } \\
\text { boro } \\
\left(\mathbf{m g ~ d m}^{-3}\right)\end{array}$ & $\begin{array}{c}\text { Reposição } \\
\text { de água } \\
(\%)\end{array}$ & $\begin{array}{c}\text { Dose de } \\
\text { boro } \\
\left(\mathbf{m g ~ d m}^{-3}\right)\end{array}$ & $\begin{array}{c}\text { Reposição } \\
\text { de água } \\
(\%)\end{array}$ & $\begin{array}{c}\text { Dose de } \\
\text { boro } \\
\left(\mathbf{m g ~ d m}^{-3}\right)\end{array}$ \\
\hline 68,2 & 0,78 & 111,3 & 0,76 & 112,2 & 0,41 & 113,6 & 0,69 \\
\hline
\end{tabular}

*matéria verde aos 55 DAS; **matéria seca aos 55 DAS; ***matéria verde aos 90 DAS e ****matéria seca aos 90 DAS.

Fonte: Elaboração dos autores.

Houve queda da matéria verde e seca das plantas aos 55 DAS (Figura 8) quando houve a aplicação de reposições de água consideradas excessivas (superiores a 100\%), e aplicações de boro superiores a $1,0 \mathrm{mg} \mathrm{dm}^{-3}$.
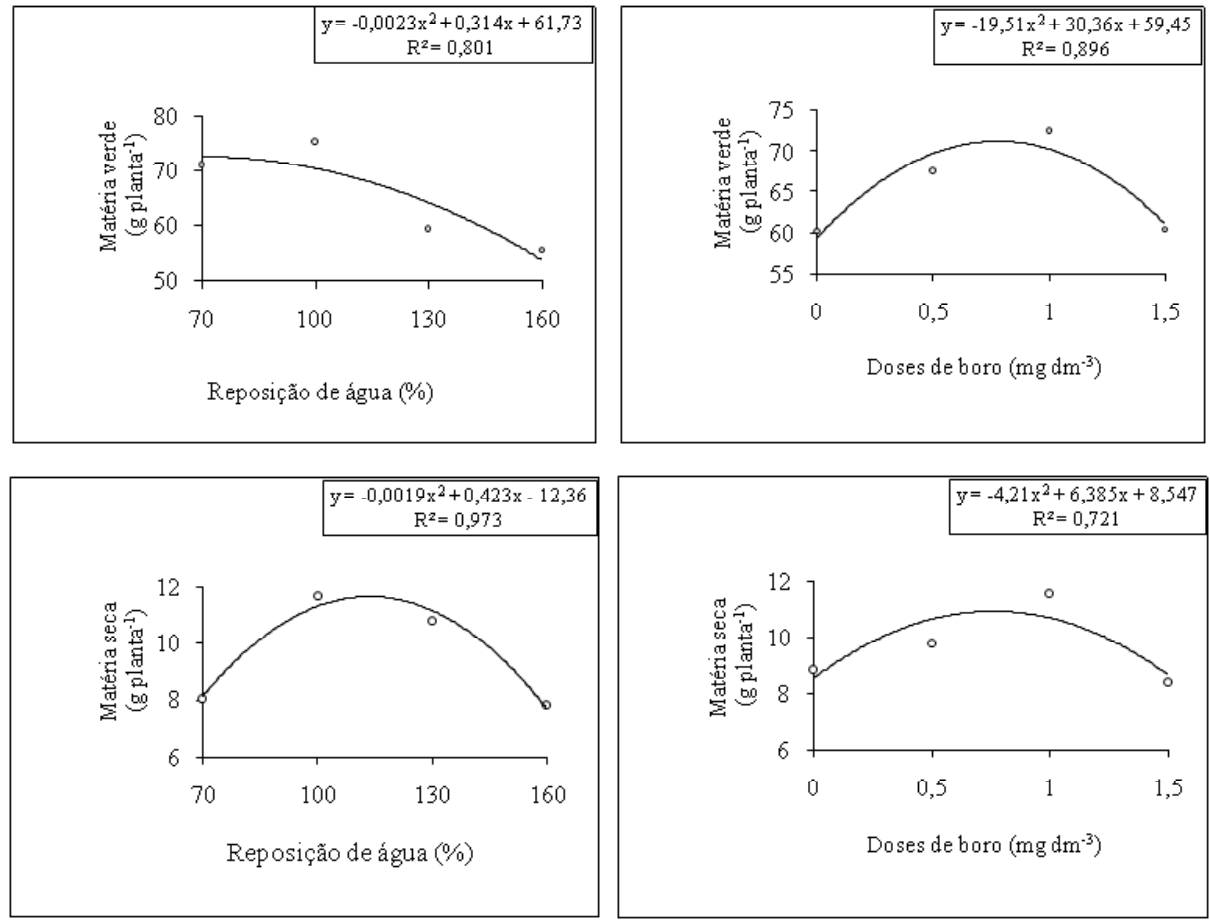

Figura 8 - Matéria verde e seca das plantas em função da reposição de água e doses de boro aos 55 DAS. Uberaba, MG, 2011.

Fonte: Elaboração dos autores

Na Figura 9, nota-se mesma tendência, porém para a data de coleta de 90 DAS. Propôs-se determinar o máximo rendimento das variáveis igualando-se a primeira derivada das equações dessas figuras a zero. Por meio da Tabela 3 pode-se verificar que a reposição de água que proporcionou a máxima matéria seca aos 90 DAS foi de $113,6 \%$ com uma dose de boro ótima de 0,69 $\mathrm{mg} \mathrm{dm}^{-3}$. 

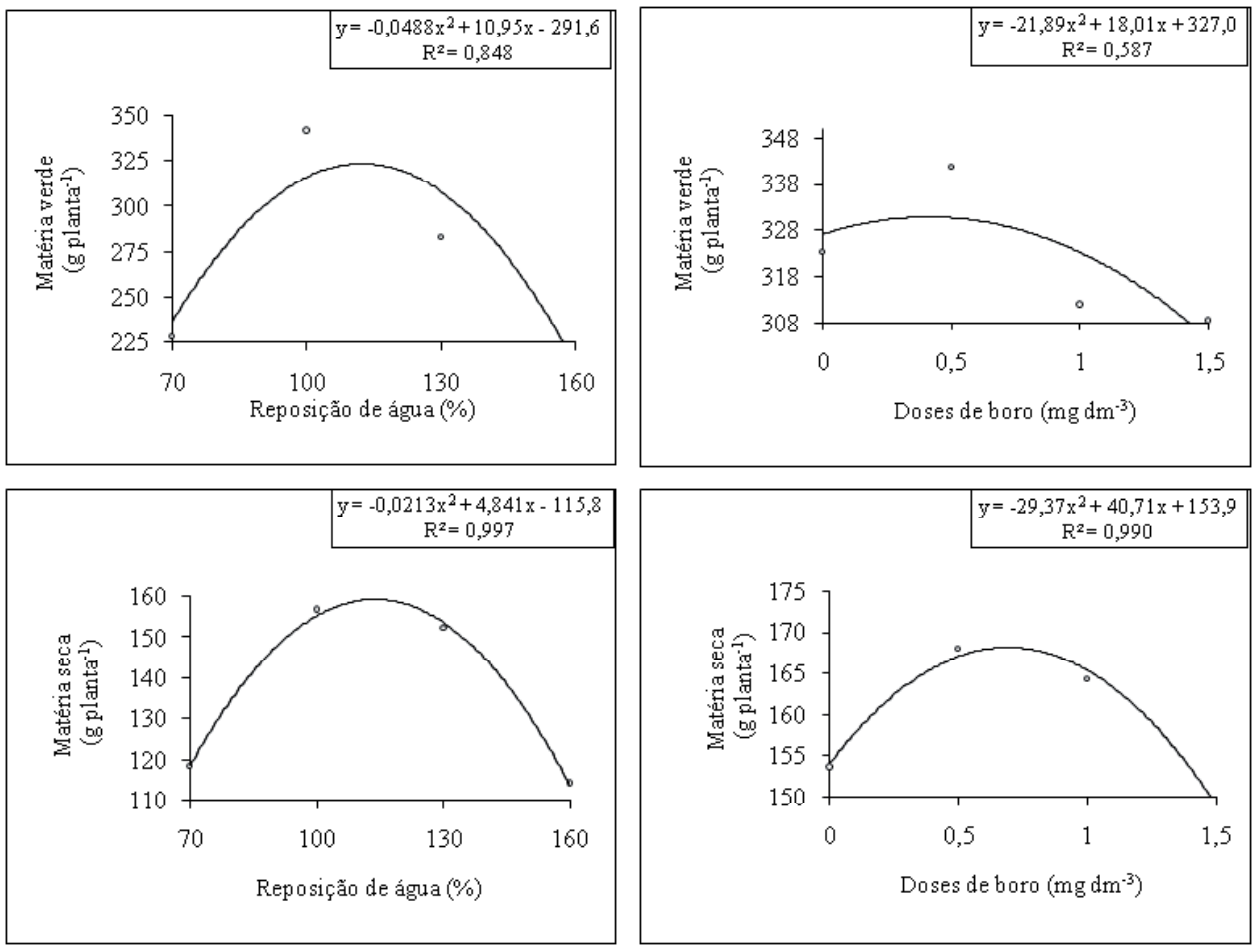

Figura 9 - Matéria verde e seca das plantas em função da reposição de água e doses de boro aos 90 DAS. Uberaba, MG, 2011.

Fonte: Elaboração dos autores.

Com o aumento da lâmina aplicada verificou-se queda da eficiência do uso da água (Figura 10). O maior valor de eficiência do uso da água foi verificado quando a irrigação foi realizada com reposição de 70\%. Valores semelhantes foram encontrados por Santana (2004). O excesso de água no solo promove, dentre outras, a asfixia das raízes diminuindo a absorção, o que acarreta queda de produtividade e uma menor eficiência do uso da água.

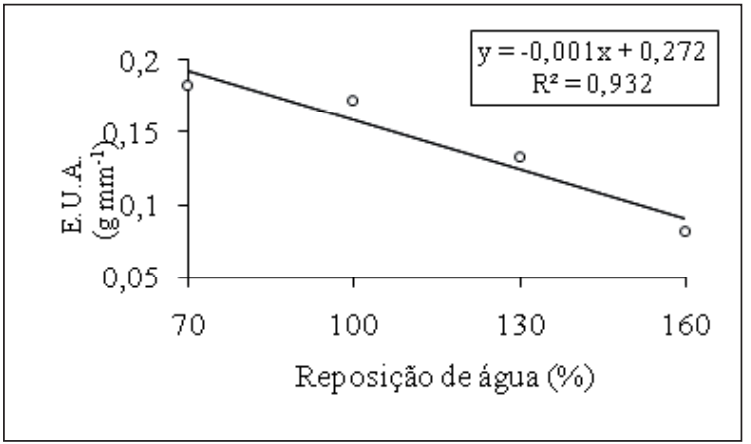

Figura 10 - Eficiência do uso da água para produção de matéria seca. Uberaba, MG, 2011.

Fonte: Elaboração dos autores.

\section{Conclusões}

A cultura do milho, cultivar 30F90, é sensível tanto ao déficit quanto ao excesso de água de irrigação. Quando se irrigou com 70\% de reposição, houve maior E.U.A. Aos 90 DAS a reposição estimada que proporcionou maior média de matéria seca foi de 113,6\% com uma dose de boro de $0,69 \mathrm{mg} \mathrm{dm}^{-3}$. 


\section{Application of boron and water replacement in soil in the crop of forage corn}

\section{Abstract}

Among the cultural treatments, both irrigation and fertilization become indispensable during the conduction of corn crop. Among the nutrients, boron plays an important role in plants' growth. It was intended to evaluate the performance of forage corn (till the cutting phase for roughage), submitted to different concentrations of boron and water replacement levels. The experimental design was completely randomized with 16 treatments (4x4), four soil water replacements $(70 \%, 100 \%, 130 \%$ and $160 \%$ of the daily evapotranspiration) and four doses of boron ( $0 \mathrm{mg} \mathrm{dm}^{-3} ; 0.5 \mathrm{mg} \mathrm{dm}^{-3} ; 1.0 \mathrm{mg}$ $\mathrm{dm}^{-3}$ and $1.5 \mathrm{mg} \mathrm{dm}^{-3}$ ) with four replicationsbeing tested. The evaluated variables were green and dry matter at 35 days after sowing (DAS), 55 DAS and 90 DAS and water use efficiency (E.U.A.). The crop cultivar $30 F 90$ is sensitive both to deficit and excess irrigation water; when irrigating with $70 \%$ of replacement, there was increased E.U.A. at 90 DAS, the estimated replacement which afforded the greatest mean of dry matter was of $113.6 \%$ with a dose of boron of $0.69 \mathrm{mg} \mathrm{dm}^{-3}$.

Key-words: irrigation management. Zea mays. Boron.

\section{Referências bibliográficas}

ALBUQUERQUE, P.E.P. de; ANDRADE, C. de L.T. de.; Planilha eletrônica para a programação da irrigação de culturas anuais. Sete Lagoas: Embrapa Milho e Sorgo, 2001. 14p. (Embrapa Milho e Sorgo. Circular Técnica, 10).

ANTONINI, J.C.A. ; GUERRA, A.F.; SILVA, D.B.; RODRIGUES, G.C. Efeito da tensão de água no solo e da densidade de plantas sobre a produtividade do milho. In: EMBRAPA. Centro de Pesquisa Agropecuária dos Cerrados (Planaltina, DF). Relatório técnico anual, 1991 a 1995. Planaltina, 1997. p. 100-102.

BERGONCI, J.I.; BERGAMASCHI, H. Ecofisiologia do milho. In: CONGRESSO NACIONAL DE MILHO E SORGO, 24., 2002. Florianópolis. Anais...Florianópolis: Embrapa Milho e Sorgo; Epagri, 2002.

BERGAMASCHI, H.; DALMAGO, G.A.; BERGONCI, J.I.; BIANCHI, C.A.M.; MULLER, A.G.; COMIRAN, F.; HECKLER, B.M.M.Distribuição hídrica no período crítico do milho e produção de grãos. Pesquisa Agropecuária Brasileira, Brasília, DF. v.39 , n9, p. 831-839, 2004.

DOURADO NETO, D.; NIELSEN, D.R.; HOPANS, J.W.; PARLANGE, M.B. Programa SWRC (Version 1.00): Soil Water Retention Curve (Software). Piracicaba: ESALQ; Davis: University of Califórnia, 1995.

FURTINI NETO, A.E.; VALE, F.R.; RESENDE, A.V.; GUILHERME, L.R.G.; GUEDES, G.A.A. Fertilidade do solo. Curso especialização em Fertilidade do solo e nutrição de plantas no agronegócio. Lavras: UFLA/FAEPE, 252 p. 2001.

GENUCHTEN, M. T. V.A closed-form equation for predicting the hydraulic conductivity of unsaturated soils. Soil Science Society American Journal, Madison, v. 50, p. 288-91, 1980.

GERVÁSIO, E.S., CARVALHO, J.A ., SANTANA, M. J. de. Efeito da salinidade da água de irrigação na produção da alface americana. Revista Brasileira de Engenharia Agrícola e Ambiental, Campina Grande, PB. UFPB. v.4 , n1, p. 125-128, 2000. 
GUERRA, A.F.; ANTONINI, J.C.A.; SILVA, D.B.; RODRIGUES, G.C. Manejo de irrigação e fertilização nitrogenada para a cultura do milho.In: EMBRAPA. Centro de Pesquisa Agropecuária dos Cerrados (Planaltina, DF). Relatório técnico anual, 1991 a 1995. Planaltina, 1997b. p. 97-98.

GUIMARÃES, C. M. Efeitos fisiológicos do estresse hídrico. In: ZIMMERMANN, M. J. O.; ROCHA, M.; YAMADA, T. Cultura do feijoeiro: fatores que afetam a produtividade. Piracicaba, Associação Brasileira para Pesquisa da Potassa e do Fosfato, 1988. p. 157-174.

MALAVOLTA, E. Elementos de nutrição mineral de plantas. São Paulo: Editora Agronômica Ceres, 1980.

PAVINATO, P. S.; CARETTA, C. A.; GIROTTO, E.; MOREITA, I. C. L. Nitrogênio e potássio em milho irrigado: análise técnica e econômica de fertilização. Piracicaba, 2007. Disponível em: <https//www. scielo.com.br>. Acesso em: 16maio 2008.

RESENDE, M.; FRANÇA, G. E.; ALVES, V. M. C. Considerações técnicas sobre a cultura do milho, Sete Lagoas: EMBRAPA-CNPMS, 1990.

SANS, L. M. A.; SANTANA, D. P. Cultivo do Milho: Clima e solo. Embrapa Milho e Sorgo, $3^{a}$.ed. 2007.

SANTANA, M.J. Produção do pimentão (Capsicum annuum L.) em ambiente protegido, irrigado com diferentes lâminas de água salina. 2004. 90p. Dissertação (Mestrado). Universidade Federal de Lavras, Lavras.

SILVA, C.A.S.; PARTIFF, T.M.B.; PORTO, M.P. Estudo do espaçamento e da população para milho em solo hidromórfico. Safra 2000/2001. In: Congresso Brasileiro de Fisiologia Vegetal. 2001. Ilhéus. Anais...Ilhéus: SBFV, 2001.

Histórico

Recebido em: 05/12/2012

Aceito em: 19/03/2014 